\section{SWOT-analiza uporabnosti e-izobraževanja za zaposlene}

C

EES, e-izobraževalni program ekonomske statistike (Course On European Economic Statistics - CEES), je prvi visokošolski e-izobraževalni program v Sloveniji. Razvoj programa CEES je potekal v okviru projekta Phare Multi-Country Cooperation in Distance Education od začetka leta 1998 do sredine leta 1999 ob pomoči mednarodnega konzorcija partnerjev. ${ }^{1}$

Temeljni cilj programa CEES je bil razvoj kakovostnega in učinkovitega e-izobraževalnega (spletnega) programa ekonomske statistike na ravni visokošolskega izobraževanja za nestatistike.

Tehnološka osnova za uresničitev zahtev, ki smo si jih zastavili pri strateškem načrtovanju razvoja programov CEES, je bila adaptacija programske podpore, ki so jo na Fakulteti za elektrotehniko Univerze v Ljubljani razvili posebej za potrebe e-izobraževanja.

Končni proizvod programa CEES je interaktivni spletni učbenik, dopolnjen s tiskanim učbenikom in zgoščenko $\mathrm{v}$ dveh izvedbah glede na to, ali imajo uporabniki dostop do svetovnega spleta ali ne.

Poskusno različico e-izobraževalnega programa CEES so testirali izredni študentje drugega letnika Ekonomske fakultete pri predmetu ekonomska statistika $v$ februarju in marcu leta $1999 \mathrm{v}$ obliki tradicionalnega študija na daljavo in v virtualnem razredu. V študijskem letu 1999/2000 smo program začeli uporabljati tudi $\mathrm{v}$ rednem študijskem procesu pri predmetih poslovna statistika in ekonomska statistika, ki ju v drugem letniku Visoke poslovne šole in univerzitetnega programa Eko- nomske fakultete posluša približno 1.500 rednih študentov, izrednih študentov in študentov študija na daljavo.

Poskusno izvedbo programa je spremljala celovita sprotna (formativna) evalvacija pedagoško-didaktičnih, programskih (softverskih) in vsebinskih vidikov programa CEES. Pri evalvaciji so sodelovali neodvisni tuji ${ }^{2}$ in domači strokovnjaki (z Ekonomske fakultete v Ljubljani in Statističnega urada RS), pedagogi in študenti.

Po poskusni izvedbi je bil pedagoško-didaktični vidik progama CEES še posebej ocenjen $\mathrm{v}$ več končnih (sumativnih) evalvacijskih postopkih, ki so potekali v okviru progra-

E-izobraževalni
program CEES se
odlikuje po inter-
aktivnem splet-
nem ucbeniku.
ma Phare in katerih nosilca sta bila Sunderland University iz Velike Britanije in Deutsches Institut für Fernstudium iz Tübingena v Nemčiji.

V nadaljevanju so prikazani rezultati evalvacijskih postopkov Sunderland University in študentskih anket, $v$ katerih je uporaba e-izobraževalnega programa CEES celovito in neposredno obravnavana.

\section{EVALVACIIIA UPORABE E-IZOBRAZZEVALNEGA PROGRAMA CEES}

\section{Poročilo Sunderland University}

Izobraževalni program CEES je v končnem poročilu evalvacije, ki jo je opravila Sunderland University, prejel zelo pozitivno oceno. Spletni učbenik si je visoko oceno prislužil mag. Mojca

Bavdaž Kveder, dr. Lea Bregar, mag. Irena Ograjenšek Ekonomska fakulteta $v$ Ljubljani 
zaradi več vidikov: različnih načinov, kako dostopati do vsebine učbenika in zunanjih spletnih virov, palete študijskih orodij, ki so vgrajena $\mathrm{v}$ spletno različico, in navigacijskih funkcij, ki preprečujejo, da bi se študent izgubil na drugih spletnih straneh. Posebej je treba opozoriti na zgoščenko kot alternativo spletnemu učbeniku, kadar je študent brez dostopa do svetovnega spleta.

Evalvacijsko poročilo potrjuje, da je izobraževalni program zastavljen tako, da spodbuja ustvarjanje znanja. To so zagotovili tudi študenti iz virtualnega razreda $v$ neposrednem pogovoru $z$ ocenjevalcem programa. Dana sta bila tudi dva predloga za izpopolnitev programa, in sicer še večja interaktivnost (na primer s prerazporeditvijo aktivnosti in nalog za vsako obravnavano temo) in sprotno ugotavljanje napredka pri študiju.

\section{Rezultati študentskih anket}

Študentje so v svojih odgovorih zelo dobro ocenili večino elementov spletnega učbenika CEES. Uporabniku je prijazen, saj se hitro naloži in omogoča enostavno sprehajanje po vnaprej začrtani študijski poti, pa tudi brskanje po spletnih virih, ne da bi se na tej poti izgubili.

Med komunikacijskimi orodji so študentje zelo visoko ocenili okno za elektronsko pošto, ki je vnaprej naslovljeno na pedagoga, diskusijske skupine pa niso zaživele zaradi zapoznelega začetka delovanja tega orodja v poskusni izvedbi, zato tudi niso bile ocenjene.
Najvišjo oceno si je prislužila izbira študijskih vsebin, sledijo mu zunanje povezave in grafična oblika besedila. Študenti so bili zelo zadovoljni s tem, da lahko osnovno znanje iz učbenika nadgrajujejo z lastnim raziskovanjem zunanjih povezav, ki so razvrščene po vsebinskih temah (poglavjih). Obenem so jim zunanje povezave služile tudi za izhodišče pri izdelavi raziskovalnih seminarjev in so tako koristnost že zbranih zunanjih povezav sami izkusili. S posebno grafično obliko besedila so lahko hitro ugotovili, ali je mogoče poiskati dodatne informacije $\mathrm{v}$ zvezi $\mathrm{z}$ označenim besedilom in kakšna vrsta povezave to omogoča. Niso pozabili opozoriti na nujnost stalnega dopolnjevanja povezav, ki poteka že deloma avtomatsko.

Ikone za navigacijske funkcije so študenti pohvalili kot zelo domiselne, pogrešali pa so klasični funkciji »Naprej《 in »Nazaj«, ki bi jih vodili zunaj začrtane študijske poti.

Zelo zadovoljni so bili z barvitim študijskim načrtom, ki nazorno kaže vsebinsko strukturo učbenika in omogoča neposredno dostopanje do posamezne vsebinske teme (poglavja), se pa nekoliko dlje nalaga.

V okviru tehnične podpore si je najvišjo oceno prislužil urejevalnik zapiskov, ki pa bi moral po mnenju študentov omogočati kaj več kot samo pisanje besedila. Kot koncept je bil visoko ocenjen tudi ukaz »Izbira vsebin«, ki omogoča izbiro posamezne teme (na primer prebivalstvo in delovna sila) ali pa posameznega sestavnega dela (angl. building block) iz vseh tem (na primer aktivnosti). V zvezi z drugimi orodji so imeli študentje nekaj pripomb, ki jih je večina že upoštevanih.

Za notranje povezave so ugotovili, da so zelo uporabne in logične. Omogočajo preskakovanje s teme na temo in tudi povezovanje različnih tem, obenem pa prihranijo čas, potreben za listanje po tiskanem gradivu. Pripomba študentov se je nanašala na to, da nas notranja povezava vedno pelje na vrh strani, čeprav je iskani del na dnu.

V povezavi s pojasnjevalnimi okni so študentske ankete odkrile slabost vmesnika: sočasno je lahko poleg osnovnega odprto samo eno pojasnjevalno okno.

Študentje so imeli do drugačnega načina študija zelo pozitiven odnos in so bili zanj zelo motivirani. Kljub manjšim zadregam so -ga 
ocenili za zelo zanimivega, privlačnega, a tudi dokaj zahtevnega, zato mu vsi niso bili kos. Ta način študija namreč zahteva poleg obvladovanja sodobne informacijske tehnologije tudi sposobnost za samostojno učenje, s katero pa se naši študenti po naših izkušnjah praviloma ne morejo ponašati. Tako so bili precej odvisni od podpore pedagoških sodelavcev, ki so jo ocenili zelo visoko. Za komunikacijo s pedagogi so uporabili različne poti (osebna srečanja, telefonske konzultacije, elektronsko pošto). To je sicer pripomoglo $\mathrm{k}$ večji individualizaciji študija, vendar se je $s$ tem povečala tudi obremenitev pedagogov.

Končna ocena študentov je, da so za predmet porabili veliko časa, saj je brskanje po spletnih straneh zamudno, še posebej če so modemske povezave slabe oziroma premalo zmogljive, vendar so $\mathrm{z}$ izobraževanjem pridobljeno znanje ocenili kot zelo kakovostno.

Izkušnje, pridobljene $\mathrm{v}$ procesu poskusne izvedbe ter evalvacije programa CEES in pri njegovi uporabi $v$ rednem pedagoškem procesu v zadnjih dveh študijskih letih (1999/2000 in 2000/2001), so bile osnova za pripravo SWOT-analize e-izobraževanja.

\section{ANALIZA PREDNOSTI, SLABOSTI, PRILOŽNOSTI IN NEVARNOSTI E-IZOBRAŽEVANJA}

Prednosti, slabosti, priložnosti in nevarnosti e-izobraževanja, ki smo jih opredelili na osnovi izkušenj z e-izobraževalnim programom CEES, so navedene $\mathrm{v}$ tabeli.

Večina elementov iz tabele po našem mnenju splošno velja za izobraževanje zaposlenih in jih je treba upoštevati, kadar se odločamo o razvoju oziroma izvedbi e-izobraževalnega programa, namenjenega zaposlenim.

Upamo, da bodo izkušnje, ki smo jih pridobili v procesu priprave programa CEES in že opisali v člankih (gl. opombo 1), koristno uporabili snovalci novih e-izobraževalnih

\begin{tabular}{|c|c|}
\hline \multicolumn{2}{|c|}{ Tabela: Prednosti, slabosti, priložnosti in nevarnosti e-izobraževanja } \\
\hline 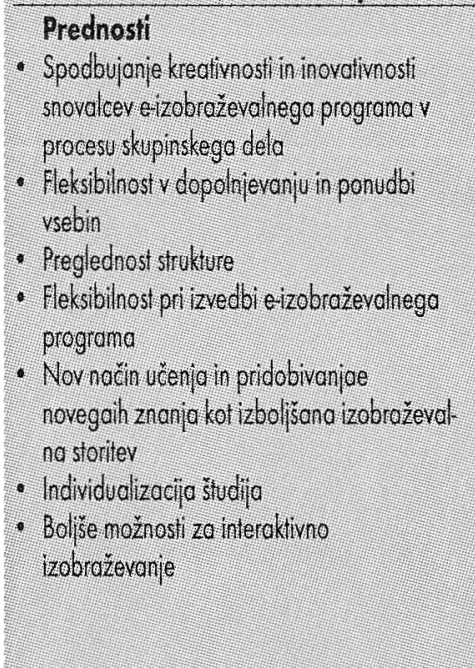 & 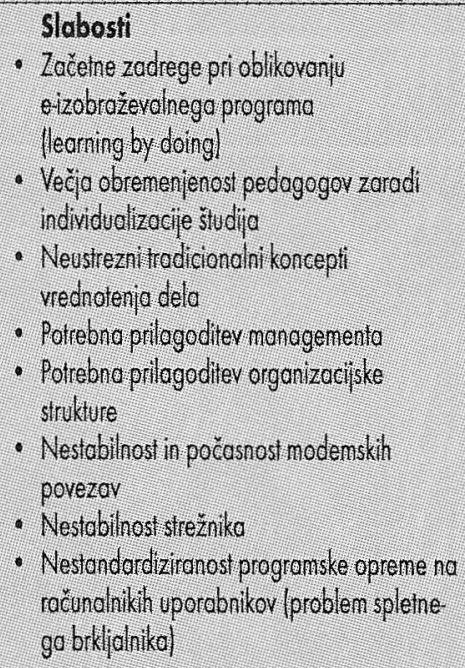 \\
\hline 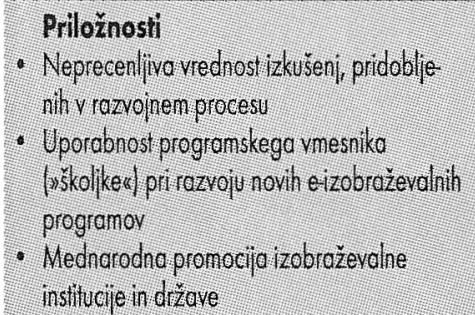 & 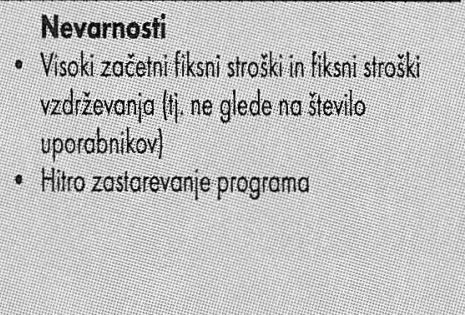 \\
\hline
\end{tabular}

programov. Želimo jim, da bi se lahko čimbolj posvetili vsebinskim vidikom priprave programa, reševanje tehnično-organizacijskih vprašanj pa prepustili za to posebej usposobljenim managerjem.

\section{SKLEPNE MISLI}

E-izobraževanje prinaša vrsto prednosti, ki so posebej zanimive za izobraževanje na delovnem mestu, na primer večja fleksibilnost izobraževanja $z$ vidika časa, kraja in vsebine izobraževanja, večja interaktivnost in hitrejši dostop do znanja iz različnih virov. Te prednosti se lahko uveljavijo le ob določenih kadrovskih, materialnih tehnoloških in organizacijskih možnostih.

Izkušnje najuspešnejših evropskih držav kažejo, da je prvi pogoj za hitrejše in dolgoročno učinkovito uvajanje e-izobraževanja v Sloveniji ustrezno materialno podprta strategija 
Opravljene raziskave (Steinbeis, 2001) kažejo, da Slovenija razpolaga s potrebno tehnološko infrastrukturo in strokovnim znanjem za uvajanje e-izobraževanja, ki se kljub temu ne razvija, kot bi se $\mathrm{v}$ danih okoliščinah sicer lahko razvijalo in moralo razvijati. Zato menimo, da se je treba bolj posvetiti zmanjševanju neskladja med zadostno tehnološko in strokovno podporo in nezrelostjo okolja za uvajanje e-izobraževanja. K temu lahko pripomore tudi seznanjanje $\mathrm{z}$ dobrimi primeri iz prakse, a le $\mathrm{v}$ omejenem obsegu.

izobraževanja za informacijsko družbo (oziroma za družbo znanja), katere pomemben segment sta vseživljenjsko izobraževanje in izobraževanje zaposlenih.

\section{LITERATURA}

Bregar, L., Bavdaž, M., Ograjenšek, I., Papič, M., Bešter, J.: On-line Course: From Experimental Use to Integration into a University Programme. Zbornik mednarodne delavnice ICL99 (Interactive Computer Aided Learning: Tools and Applications) na zgoščenki. Beljak/Villach: Technikum Kärnten, 1999.

Bregar, L., Ograjenšek, I., Bavdaž, M.: Teaching Economic Statistics in a Digital Environment. V: Ferligoj, A., Mrvar, A. (ur.): New Approaches in Applied Statistics. Metodološki zvezki 16. Ljubljana: Center za metodologijo in informatiko na FDV, 2000, str. 237-249.

Steinbeis: Issues and Challenges in E-learning in the Context of Lifelong Learning in the Candidate Countries. Reutlingen: Transfercentre, 2001, str. 7.

1 Osnovne značilnosti in izhodišča za razvoj programa CEES smo opisali v številnih člankih. Dva od njih sta navedena $v$ seznamu literature.

2 Samoiniciativno so nas za pregled oziroma možnost evalvacije zaprosili predstavniki iz nacionalnih statističnih uradov iz Kanade, Avstralije, Avstrije, Makedonije, Irana, Belgije, mednarodnega statističnega inštituta (ISI) ter statističnega inštituta za Azijo in Pacifik (SIAP). 